\title{
Pain experience in children with juvenile idiopathic arthritis on TNFalpha-inhibitors
}

\author{
JH Jeppesen*1, T Herlin ${ }^{2}$ and $M$ Thastum $^{1}$
}

Address: ${ }^{1}$ Department of Psychology, University of Aarhus, Aarhus, Denmark and ${ }^{2}$ Aarhus University Hospital, Skejby, Aarhus, Denmark

* Corresponding author

from 15th Paediatric Rheumatology European Society (PreS) Congress

London, UK. 14-17 September 2008

Published: 15 September 2008

Pediatric Rheumatology 2008, 6(SuppI I):PI69 doi:10.II86/I546-0096-6-SI-PI69

This abstract is available from: http://www.ped-rheum.com/content/6/SI/PI69

(C) 2008 Jeppesen et al; licensee BioMed Central Ltd.

\section{Background}

The use of TNFo-inhibitors has proven its efficacy in children with severe juvenile idiopathic arthritis (JIA) unresponsive to standard therapy. Pain reduction or elimination could therefore be expected. However, multiple factors besides disease activity contribute to the pain experience in children with JIA.

The aim of this study was to examine pain experience in children treated with TNFo-inhibitors, and whether it was associated with pain-specific beliefs and pain-coping strategies.

\section{Materials and methods}

Children with JIA treated with TNF $\alpha$-inhibitors $(\mathrm{n}=42$, mean age $13.4 \pm 2.4$ years, $69.0 \%$ girls) completed the Pain Coping Questionnaire, a revised version of the Survey of Pain Attitudes, and a 2-week pain diary (range 05). A composite arthritis activity score was calculated (range 0-9).

\section{Results}

The mean arthritis activity score was $0.9 \pm 1.7$ (range $0-9$ ) and the mean average score of pain was $1.0 \pm 1.2$ (range $0-4.7)$. Thirteen children $(31,0 \%)$ reported pain every day (average pain score $=2.3$ ). The arthritis activity and the pain experience didn't correlate significantly $(r=0.203$, $p$ $=0.221$ ). Significant correlations were obtained between the pain experience and the pain-coping subscale of catastrophizing, the pain belief subscales of disability, harm, emotion, and solicitude.

\section{Conclusion}

The results indicated that pain was still a considerably problem in our sample, even though many of the children were in remission with biological agents. No association was found between the arthritis activity and the pain experience,

Health beliefs and use of the pain-coping strategy catastrophizing were significantly associated with the pain experience in children with JIA treated with TNF $\alpha$-inhibitors. 